\title{
The role of structured handouts in improving the teaching learning process of final year MBBS students
}

\author{
Babu Raj Stephenson ${ }^{1}$. Belgin P.K. ${ }^{2}$ \\ ${ }^{1}$ Dr.Babu Raj Stephenson, Professor, ${ }^{2}$ Dr. Belgin Prem Kumar, Assistant Professor, both authors are affilited with \\ Department of Paediatrics, Dr. S.M.C.S.I Medical College, Trivandrum, Kerala, India.
}

Address for Correspondence: Dr. Babu Raj Stephenson, Email id: drsbaburaj@gmail.com

\begin{abstract}
Introduction: Teaching includes application of various teaching learning methods by a teacher to transfer knowledge and skills to a student. It requires a lot of effort and talents to modify the method more effectively, to communicate the ideas more easily and artistically. It is important to design tutorials and lectures according to audience perspective. Handouts for lectures have always been a much debated subject between teachers and students. This study was done to analyze whether the structured handouts enhance the learning outcomes of medical students. Methodology: Data for the study was collected from final year MBBS students, using a Randomized controlled study design. The participants were divided randomly assigned to any of the three methods, pre handout, post handout, no handout together with traditional lecture class. Six pediatric lecture topics were taken. The three groups were assessed using post test in addition to the feedback collected from students. PValue $<0.05$ was considered as significant. Results: Comparison of post test scores among the three groups (pre handouts, post handouts and without handouts) does not show statistical significant $(\mathrm{p}=0.683)$. Even though the post test score of the 'without handout' group was marginally better than the 'handout' group, it was not statistically significant ( $p$ value $=0.557$ ). Most of the participants are in favour of handouts. Analysis of variance test did not show any expected variation according to mode of administration. There was no significant difference in student's performance among the three groups. Post test scores were almost similar in all the three groups (pre handouts, post handouts \& no handouts). Conclusion: Majority of the students felt that providing handouts during lectures was a better method which enhanced their understanding and scoring. But while comparing the learning outcomes of 'handouts groups' and 'no handouts groups' using post test score, it was found to be statistically not significant.
\end{abstract}

Key words: Effective Teaching, Handouts, Learning Outcome, Lecture, Teaching Learning Methods, Teaching Practice

\section{Introduction}

Teaching method includes various modes applied by a teacher to achieve the desired learning in students. Of course, these strategies are partially developed according to the learner. Increase in the number of students and wide areas to be covered in less time and more focused sessions made inevitable a reappraisal of how teaching can be delivered sustainably with systems such as tutorials, visual or video aids and discussions together with black board and ordinary lectures. Studies point out that,

Manuscript received: $6^{\text {th }}$ August 2017

Reviewed: $16^{\text {th }}$ August 2017

Author Corrected: $24^{\text {th }}$ August 2017

Accepted for Publication: $31^{\text {st }}$ August 2017 cognitive load theory has effects on the different options mentioned above [1]. Teachers always keep thinking to modify their teaching and learning skills. It requires a lot of effort and talent to modify the method more effectively, to communicate the ideas more easily and artistically. Changes in teaching practice, student's expectations, technology and demographics have resulted in the development of various new methods of teaching from traditional approaches.

Most of the students face challenges in taking complete notes and in many cases they prefer to be provided with complete and comprehensive notes 
[2]. Teachers apply different skills and arts in their teaching session for effective teaching. Many teachers use the method of distribution of printed notes (handouts) to students in advance, as a part of teaching programme. Selection of learning materials is an integral part of curriculum planning. The learning and the teaching resources provide a source of learning experience to the students.

In spite of its limitations, lecturing is the most commonly used method of teaching in higher education. As a result of advanced technology, costcontainment pressures and a desire to make innovative improvements in medical education, dramatic changes have occurred in planning and delivery of lecture and its handouts [3, 4]. Assessment of students learning at each time, known as clicker method would improve the effectiveness of teaching method further [5]. It is important to understand the targeted group of student's various levels (ability of learning, interest) in advance. Also for various groups and different topics, effective mode may differ. It is important to design tutorials and lectures according to audience perspective.

Many Institutions and individuals are now routinely publishing lecture handouts on the web for students to access [4]. Lecture handouts are widely used as instructional tools. Handouts make the lectures "portable and enduring" and lead to improved recall of information and improved test performance [6].

From students' point of view, the main strength of handout is, it acts as a guide for learning and revision before examination.

The handouts are expected to be clear, brief, well structured in simple language and compilation of summary from standard textbooks. Although handouts are widely used as instructional tools, little research has been done on conventional paperbased, and also on computer-based and web-based handouts [7].

The students show greater demand for learning resources, especially lecture handouts [8]. It is often necessary to guide them through handouts, as they may not be matured enough to manage their time for learning and to look for the right references. Teachers expect that lecture handouts should supplement rather than substitute students' regular reading [8].

The students who do not have handouts have to do a bit more work to achieve the same grade as those who were given handouts. The decision to issue lecture notes is related to a number of factors: viz; the teaching style of the lecturer, the nature of the subject matter, and the availability of written and other resources in the subject area [9].

Having handout in hand, students can make a link between what they see on the projector board and what they have in written text format. With this approach simultaneous audio-verbal, visual and written text communication modalities are involved to clarify the educational context and to promote learning [10]. Another important aspect of handouts is that distributing handouts may cause a positive relationship between the instructor and students and also creates a more interesting and attractive educational atmosphere [10].

The preparation of good quality lecture notes is time-consuming and their reproduction is probably costly. Handouts for lectures have always been a much debated subject between teachers and students.

It is also important to validate our sessions to identify the effectiveness of mode of our teaching according to the nature of students and type of subject we handle. Clickers, follow up emails to give students their own marks together with feedback can help teaching more systematic.

\section{Objective}

To find out the effectiveness of structured handouts in comparison with no handouts in teaching learning process of the final year MBBS students attending Paediatric lectures using Post Test Scores.

\section{Methodology}

This study was conducted at Dr. S.M. CSI. Medical College, Karakonam, Trivandrum. The present study has been conducted as part of a training program to improve the teaching skills of faculties in medical profession. Study period was two months. Ethical permission was obtained from the ethical committee of the Dr SM CSI medical college followed by scientific committee review of the protocol. 
Study Design- Data for the study was collected using a Randomized controlled study design. The participants were divided randomly with the help of random number tables in to three groups and one group (pre handout) will be given the structured handout one day prior to the lecture class, while the other group(post handout) received the handouts immediately after the lecture class. The third group (without handout) received the handouts only after the assessment. Six pediatric lecture topics were taken while the pre handout, post hand out and without handout groups were rotated in turn. All the six topics were covered by same principal investigator, in order to avoid variation in the mode of administration.

The three groups were assessed on next day with carefully prepared ten Multiple Choice Questions (MCQ) and the score was taken as the outcome of the learning process. After the completion of the study, students feed- back was obtained by using a self structured questionnaire to identify the effectiveness of structured handouts for improving the students performance.

\begin{tabular}{|c|c|c|c|c|c|c|}
\hline Topic & Name of Topic & $\begin{array}{c}\text { Date of } \\
\text { lecture } \\
\text { taken }\end{array}$ & $\begin{array}{c}\text { Pre } \\
\text { Handouts }\end{array}$ & $\begin{array}{c}\text { Post } \\
\text { Handouts }\end{array}$ & $\begin{array}{c}\text { Without } \\
\text { Handouts }\end{array}$ & $\begin{array}{c}\text { Post test } \\
\text { date }\end{array}$ \\
\hline 1 & $\begin{array}{c}\text { Acute Glomerulonephritis } \\
(\text { AGN) }\end{array}$ & $06 / 11 / 15$ & A group & B group & C group & $07 / 11 / 15$ \\
\hline 2 & $\begin{array}{c}\text { Urinary Tract Infection in } \\
\text { children (UTI) }\end{array}$ & $13 / 11 / 15$ & B group & C group & A group & $14 / 11 / 15$ \\
\hline 3 & Nephrotic Syndrome & $20 / 11 / 15$ & C group & A group & B group & $21 / 11 / 15$ \\
\hline 4 & Vesico Ureteric Reflex(VUR) & $27 / 11 / 15$ & A group & B group & C group & $28 / 11 / 15$ \\
\hline 5 & Hemolytic Uremic Syndrome & $04 / 12 / 15$ & B group & C group & A group & $05 / 12 / 15$ \\
\hline 6 & $\begin{array}{c}\text { Congenital Abnormalities of } \\
\text { Kidney and Urinary Tract }\end{array}$ & $11 / 12 / 15$ & C group & A group & B group & $12 / 12 / 15$ \\
\hline
\end{tabular}

Inclusion criteria- All the final year MBBS students of a Medical College in South Kerala, India

Exclusion criteria- Students those who were absent during randomization were not included in the study.

Study variables- Various groups, topics, mode of administration (pre handout, post handout, no handout), Post test scores obtained by the students one day after the session.

Sample Size- A total of 96 final year MBBS Students were included and all completed the study.

The data's were entered in the excel sheet and analyzed by ANOVA statistical test using the SPSS soft ware.

\section{Results}

In this study, 96 students were enrolled and randomized into three groups (pre handout, post handout and without handout).

Table-1: Comparison of post test score for the 6 lectures.

\begin{tabular}{|c|c|c|c|c|c|c|}
\hline & \multicolumn{2}{|c|}{$\begin{array}{c}\text { Test score } \\
\text { Pre-handouts }\end{array}$} & \multicolumn{2}{c|}{$\begin{array}{c}\text { Test score } \\
\text { Post handouts }\end{array}$} & \multicolumn{2}{c|}{$\begin{array}{c}\text { Test score } \\
\text { No handouts }\end{array}$} \\
\cline { 2 - 7 } & Mean & SD & Mean & SD & Mean & SD \\
\hline Topic 1 & 7.35 & 2.27 & 7.31 & 2.13 & 7.87 & 1.89 \\
\hline Topic 2 & 8.13 & 2.47 & 8.00 & 2.22 & 7.81 & 2.40 \\
\hline Topic 3 & 6.40 & 1.43 & 5.81 & 1.96 & 6.06 & 1.87 \\
\hline Topic 4 & 6.65 & 2.30 & 5.94 & 2.51 & 7.07 & 2.39 \\
\hline Topic 5 & 7.31 & 2.19 & 8.40 & 1.84 & 7.48 & 2.06 \\
\hline Topic 6 & 6.47 & 1.36 & 5.87 & 1.99 & 6.06 & 1.87 \\
\hline
\end{tabular}


In table 1 , test scores for topic 1 and topic 4 seems statistically similar, even though "no handout" score seems better. For topic 2, topic 3 and topic 6, "pre handout" score seems better. We also observed that for topic 3 and topic 4, "post handout" score were worse at the same time that was found to be better for topic 5 (table 1).

Also analysis of variance test was conducted to identify the difference in post test scores according to the various methods (pre- hand out, post handout and no handout) and found that, scores were not statistically significant ( $p$ value $=0.658$ ) according to methods of administering the lecture class for various topics.

Table-2: Comparison of post test scores among the three groups (pre handouts, post handouts and without handouts).

\begin{tabular}{|c|c|c|c|}
\hline & $\begin{array}{c}\text { Pre-handout } \\
(\mathbf{n}=\mathbf{1 9 2})\end{array}$ & $\begin{array}{c}\text { Without handout } \\
(\mathbf{n}=\mathbf{1 9 2})\end{array}$ & $\begin{array}{c}\text { Post handout } \\
(\mathbf{n}=\mathbf{1 9 2})\end{array}$ \\
\hline Mean & 7.0 & 7.1 & 6.9 \\
\hline SD & 2.2 & 2.2 & 2.4 \\
\hline Median & 8.0 & 8.0 & 8.0 \\
\hline Mode & 6.0 & 8.0 & 8.0 \\
\hline Minimum & 0.0 & 2.0 & 2.0 \\
\hline Maximum & 10.0 & 10.0 & 10.0 \\
\hline
\end{tabular}

In table 2, descriptive scores for various methods (pre, post and no handouts) were given. Mean score was observed to be higher in without handout and worse in post handout, but at the same time we obtained same median scores (table 2).

Post test scores for various methods (pre handout, post handout, no handout) are given using box plot in figure 1.

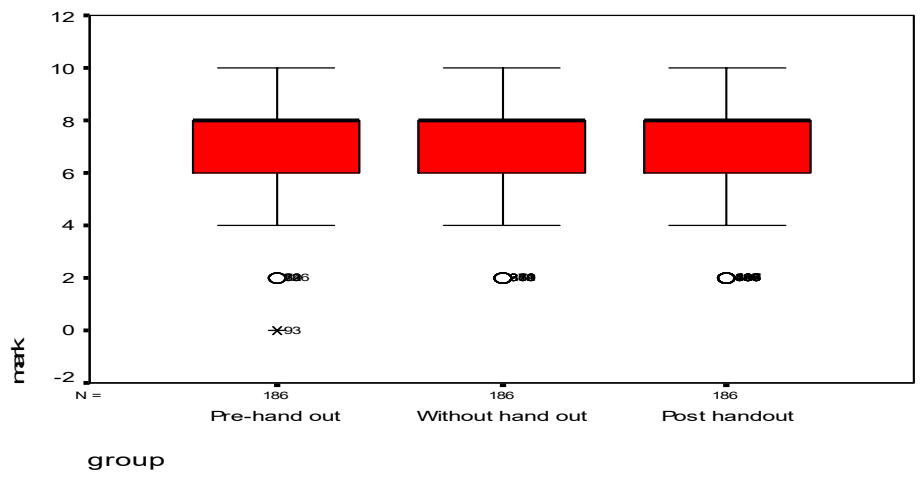

Figure-1: Comparison of post test score.

In Figure 1, there was no significant difference in the post test scores of the three groups.

Table-3: Effectiveness of structured handouts in comparison with no handouts in teaching learning process

\begin{tabular}{|c|c|c|}
\hline & $\begin{array}{c}\text { Handout (pre and post together) } \\
(\mathbf{n}=\mathbf{3 8 4})\end{array}$ & $\begin{array}{c}\text { Without handout } \\
(\mathbf{n}=\mathbf{1 9 2})\end{array}$ \\
\hline Mean & 6.9 & 7.1 \\
\hline SD & 2.3 & 2.2 \\
\hline Median & 8.0 & 8.0 \\
\hline Mode & 8.0 & 8.0 \\
\hline Minimum & 0.0 & 2.0 \\
\hline Maximum & 10.0 & 10.0 \\
\hline
\end{tabular}


Further pre and post handout joined into "handout group" and compared with "no handout group" (table 3). "No handout group" performance was visibly better compared to "handout group" and also tested these groups to find out if any difference in performance scores between "handout" and "no handout" group using t- test. It was found that, performance score for these two groups were not significantly different ( $p$ - value=0.557) (figure 2).

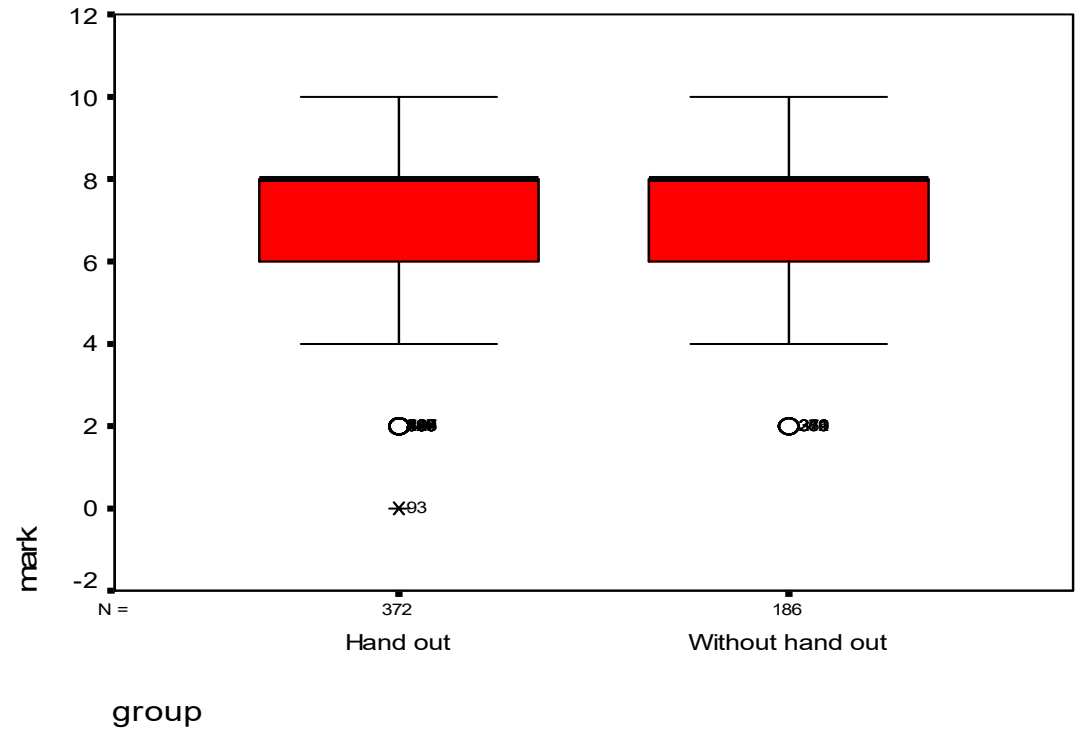

Figure-2: structured handouts in comparison with no handouts in teaching learning process

Table 4: Students opinion on pre handout.

\begin{tabular}{|c|c|}
\hline $\mathrm{n}=96$ & Frequency (\%) \\
\hline Better Method & $93(96.9 \%)$ \\
\hline Easy to understand & $89(92.7 \%)$ \\
\hline Interesting to learn & $83(86.5 \%)$ \\
\hline Helped in scoring exam & $91(94.8 \%)$ \\
\hline
\end{tabular}

From the collected feedback, the student's interest on structured handouts was obtained. Most of the participants are in favour of structured handouts for lectures for various reasons like better method (96.9\%), easy to understand (92.7\%), Interesting to learn (86.5\%) and helped in scoring examination (94.8\%) (Table 4).

\section{Discussion}

The present research was conducted to find the effective teaching learning method; namely lecture without handouts, lecture with hand outs distributed immediately after the session (post handout) and Lecture with handouts distributed one day before the session (pre handout). Students for the three groups were assigned randomly.

Six pediatric lecture topics were taken while the pre handout, post handout and without handout groups were rotated in turn. We expected better performance among the students with pre handout than the other two groups; but there was no significant difference in students performance among the three groups. Similar results were already reported by a study conducted by Seery M (2013) that, even though students who did not have handouts, spent slightly longer on lecture notes, the end result for the groups were same, although, "no handout" group put more effort to get the level of other groups[11].

Providing material in advance helps students to understand the lecture information more readily. Providing the material afterwards means that the students have to work harder during lectures, but this work can be a benefit to learning ("desirable difficulties"). 
This study replicated the finding of Seery M (2013) that, giving handouts in lectures did not significantly enhance the students performance [11]. As we randomized the students in to three groups, the academic performance due to students' variability becomes equally distributed to the three groups. In addition, the teacher and the sessions were same to the three groups and the only difference was the teaching method (handout or no handout).

The learning outcome of both groups (handouts \& no handouts) were the same, as evident in Figure 2. This might be due to lack of focus in class. Previous studies have reported that taking class notes improve the focus in class which ultimately improve the outcome performance, deeper levels of content transmission and understanding [12],[13],[14].

Different studies has shown that students who had taken partial note performed better in examinations and also in answering conceptual questions compared to students who received full notes[15],[16]. Receiving full notes also has a negative effect on class attendance motivation [17]. Taking lecture notes by students during class hours is a common practice, that helps them transferring the educational content very well [10].

The study by Austin J.L et al Results indicate using slides with or without guided notes was superior to traditional lecture with regard to critical points and examples [18]. Partial notes distributed to the students while listening to a lecture resulted in higher scores on the essay test [19].

Majority of students felt that distributing handouts was a better method which helped them to understand, score and kindled their interest (table 4). A study done by Farnaz Z (2013) also reported that students were in favor of distribution of lecture handouts for better understanding [10].

Limitations of the study- All the students in these three groups were classmates since they joined the college for the medical course. Participants were facing their final semester examination, and so they were serious and conscious about academics. Students were prior informed about the handouts and the randomly selected groups for different method of administration (handout versus no handout). Due to this prior information, the study materials which were distributed to the assigned group would have acquired by other students to prepare for the forthcoming tests. Communication modes and connectivity have improved and all students are well equipped with mobiles and laptops. This would have resulted in easy availability of the handouts to the non handout group. The tests scores of all the groups are almost similar because the students are always aware of internal assessment marks and would have prepared well for the exams. The use of 10 MCQs for assessment of each topic may not be adequate for the assessment of learning outcome. More over the student are not relying heavily on lecturers or lecture handouts for the assessment test.

\section{Conclusion}

Majority of the students' felt that providing handouts during lectures was a better method which enhanced their understanding and scoring. But while comparing the learning outcome of 'handouts groups' and 'no handouts groups' using post test score, it was found to be statistically not significant.

Hence structured lecture handouts can be used for generating interest and better understanding of the subjects in Medical Education.

1. Giving lecture handouts before and after lecture may not improve the cognitive gain.

2. Providing lecture handouts may improve the understanding of lecture and hence the students want to have lecture handouts.

3. Method of teaching should be selected according to the topics.

4. Giving full handouts also have a negative effect on active attending the class and academic performances.

Funding: Nil, Conflict of interest: None initiated, Perission from IRB: Yes

\section{References}

1. Marsh, E. J. and Sink, H. E. (2010), Access to handouts of presentation slides during lecture: Consequences for learning. Appl. Cognit. Psychol., 24: 691-706. doi:10.1002/acp.1579

2. Van Der Meer, J. Students' note-taking challenges in the twenty-first century: considerations for teachers and academic staff developers." Teaching in Higher Education 2012. 17(1): 13-23. Doi:10. $1080 / 13562517.2011 .590974$. 
3. Wofford MM, Spickard AW 3rd, Wofford JL. The computer-based lecture. J Gen Intern Med. $2001 \mathrm{Jul} ; 16(7): 464-7$.

4. Rous BA, Rashbass JL. What can Internet technology add to pathology education? Histopathology. 2002;41(Suppl 2):216-21.

5. Mohammed Nazrul Islam, Md. Anwarul Azim Majumder, Rogayah Ja'afar, Sayeeda Rahman. Students' Perceptions of 'Technology-Based' Lecture Handouts The Malaysian Journal of Medical Science 2005 Jan; 12(1): 26-28.

6. Kroenke K. Handouts: making the lecture portable. Med Teach. 1991;13(3):199-203.

7. Brown G, Tomlinson D. How to... Improve Handouts. Med Teach. 1980;2(5):215-20. doi: 10. $3109 / 01421598009081192$.

8. Vaz M. What do students expect of lecture handouts during the first year of the medical curriculum. Med Teacher. 1999;21:324-5

9. Gibbs, G., S. Habeshaw and T. Habeshaw. 53 interesting things to do in your lectures $4^{\text {th }}$ ed. Bristol: Technical \& Educational Services, 1992

10. Farnaz Zahedi Avval1, Lida Jarahi, Kiarash Ghazvini, and Masoud Youssefi International Journal of Education and Research 2013. Vol. 1 No. 12).

11. Michael Seery, Do you use lecture handouts, and when? cognitive load theory, lecture handouts. 2013 (http://michaelseery.com/home/index.php/2013/10/d o-you-use-lecture-handouts-and-when/)
12. Piolat, A., T. Olive. Cognitive effort during note taking." Applied Cognitive Psychology. 2005. 19 (3) :291-312.

13. Trickett, S. B. and J. G. Trafton. Note-taking as a strategy for learning. Proceedings of the Twenty First Annual Conference of the Cognitive Science Society: 1999. 742-748.

14. Bohay M, Blakely DP, Tamplin AK, Radvansky GA. Note taking, review, memory, and comprehension. Am J Psychol. 2011 Spring; 124 (1): 63-73.

15. Russell, I. J., Caris, T. N. Effects of three types of lecture notes on medical student achievement." J Med Educ. 1983. 58(8): 627-636. journals.sagepub. com/doi/abs/10.1177/0265532211415379

16. Katayama A. D., Robinson D. H. Getting students "partially" involved in note-taking using graphic organizers." Journal of Experimental Education. 2000;68(2): 119- 133.

17. Tara L. Cornelius and Jamie Owen-DeSchryver. Differential effects of full and partial notes on learning outcomes and attendance." Teaching of Psychology. 2008. 35(1): 6-12. DOI: 10.1080/ 00986280701818466

18. Austin, J. L., Lee, M. G., Thibeault, M. D., Carr, J. E., \& Bailey, J. S. Effects of guided notes on university students' responding and recall of information. Journal of Behavioral Education, 2002; 11, 243-254.

19. Annis, L. F. Effect of preference for assigned lecture notes on student achievement. Journal of Educational Research, 1981;74, 179-182. http://dx. doi. org/10.1080/00220671.1981.10885306

\section{How to cite this article?}

Babu Raj Stephenson. Belgin P.K. The role of structured handouts in improving the teaching learning process of final year MBBS students. J PediatrRes.2017;4(08):497-503.doi:10.17511/ijpr.2017.i08.01. 